\title{
Actividacles Universitarias
}

Las Escuelas de Farmacia y Quimica Industrial de Concepción.-De la Memoria presentada al Directorio de la Universidad sobre el funcionamiento de las Escuelas de Farmacia y Química Industrial. y que lleva la firma del Director de esfas Escuelas, don Solvador Gálvez, entresacamos los datos que se inserfan a continuación.

\section{ESCUELA DE FARMACIA}

Desarrollo de la enseñanza.-En iguales condiciones a las conocidas de normalidad, se mantuvo la instrucción profesional proporcionada por esta Escuela en el año 1923

El mismo propósito de hacerla a la vez técnica y práctica, conforme a los mejores mandatos pedagógicos. la caracterizó y determinó.

Dentro de la idea de salvar los inconvenientes propios del mantenimiento de un cuarto año de estudios, que quedaron evidenciados en 1922, y atendiendo a la aspiración de completar la enseñanza tradicional de los estudios farmacéuticos en la forma que ha sido acordada y conoce el $\mathrm{H}$. Directorio de la Universidad, en el curso del año 1923 fueron introducidas en la instrucción, en los cursos que se indican, las siguientes asignaturas:

Contabilidad, en el primer año:

Legislación y Quimica Analítica Superior, en el segundo; y

Práctica de Cirugia Menor y Química Industrial Farmacéutica, en el tercero.

Se mantuvo también, en calidad de voluntaria, la cátedra de Bacteriología.

El objetivo perseguido con la introducción del aprendizaje de las asignaturas que quedan enunciadas, no ha sido otro que el de habilitar. del modo más eficaz posible, a los futuros profesionales, para hacer frente a cuantas cuestiones se les susciten en el ejercicio de su carrera.

Esludiantes que obfuvieron su lifulo.-Durante el año 1923 obtuvieron su titulo profesional 19 alumnos. Dicha cifra envuelve la totalidad de los estudianles que se presentaron a rendir sus pruebas en el año mencionado, no habiendo que lamentar un solo fracaso. Los alumnos recibidos en 1923 son los siguientes: señoritas Luisa Alarcón, Lidia Barrientos. Florencia Concha, Amalia Vidal, Juana Inostroza, Elza González. Elena de Vivié. Paulina Rubio. Laura Duvauchelle. Flora Hermosilla. Luzvira Ortiz, Juana Canales, Inés Santander, y Odilia Hurtado: y los señores Guillermo Maldonado. Justiniano Herrera. Juan Zemelman. Gonzalo Torres y Ricardo Wortsman. Agregados a los 14 profesionales ya recibidos en la Escuela, se obtiene un tolal de 33 niñas y jóvenes que han alcanzado su titulo gracias a sus servicios.

Es grato, además, dejar constancia de que todos estos profesionales se en- 
cuentran trabajando en diversas ciudades del país, en forma que es una prueba de la confianza que sus conocimientos han llegado a inspirar.

Formacia Modelo.-La Farmacia Modelo ha seguido llenando, desde el punto de vista de la enseñanza. el fin para el cual fué establecida. Desde el punto de vista comercial, tampoco su giro, en 1923, ha sido favorable, pues se consiguió cerrar el año con una ganancia liquida superior a dos mil pesos.

Actividades esfudianfiles.- En 1923 los estudiantes de la Escuela de Farmacia, como en los años anteriores, se han mantenido organizados en un centro que ha desarrollado alguna actividad. Han celebrado, además, fiestas de compañerismo estudiantil.

Ante el año 1924.-Llega la Escuela de Farmacia al año 1924 con sus servicios docentes ya definitivamente en funciones.

Para corresponder a los anhelos de adelanto sobre que se asentado su creación, no se tiene ya sino el objetivo de afianzar y hacer más eficaces las condiciones en que se ha desenvuelto su acción.

Finalidad inmediata para ello ha sido la ampliación del edificio en que se encuentra insfalada, cuyo logro será un hecho desde comienzos de 1924. Las obras que en el edificio se ejecutan y que se terminarán muy pronto. significarán un evidente progreso en cuanto a comodidad y confort para profesores y estudiantes.

Otro tanto cabe expresar respecto a las nuevas adquisiciones de material de enseñanza que se harán efectivas en el curso del año.

La Farmacia Modelo, sus laboratorios técnicos, completan la obra en cuanto al propósito de servir las necesidades pertinentes de la ciudad y la región. Mención especial debe merecer, a este respecto, el Laboratorio Clínico y de Opoterapia. que iniciará sus funciones en 1924.

\section{ESCUELA DE QUIMICA INDUSTRIAL}

Desarrollo de la Enseñanza.- La instrucción de esta Escuela se ha desenvuelto, como en los años anteriores, con entera normalidad.

A comienzos de año, consultando un pensamiento más cientifico y armónico. se introdujeron en el plan de estudios algunas modificaciones que, inmedialamente, fueron puestas en práctica.

La preocupación, desde hace tiempo existente, en orden a la asignatura Química Industrial, pudo ser también satisfactoriamente despejada, pues, desde comienzos de año se ha contado con la cooperación del profesor contratado de Quimica Industrial. Dr. Sr. Kurt Reisenegger. que ha tenido a su cargo dicho ramo.

Incremento de los Laboraforios.-Atención especial de la Dirección de la Escuela ha debido merecer la conservación e incremento de los laboratorios. cuya función aparece como esencial en categoria de estudios como los que suministra. que deben descansar principalmente en la experimentacion. Se ha cuidado. por esto, de manfener en condiciones eficaces los Laboratorios de Química Inor- 
gánica, Química Analítica y Química Orgánica. Microscopia y Máquinas y Electricidad, de los cuales, estos últimos, funcionan desde 1923 en pabellones construidos para el objeto.

Excursiones.-La práctica de las excursiones y viajes de estudio de los alumnos se ha mantenido en 1923. dentro de la idea de que ella es abiertamente beneficiosa para la marcha de la enseñanza.

De este modo. los alumnos de los distintos cursos han visitado en la ciudad la mayoría de los establecimientos fabriles que existen y han ampliado sus excursiones a Lirquén. Penco y Nonguén.

Los estudiantes del $30^{\circ}$ y $42^{\circ}$ años hicieron, además, una jira de visita y de estudio al Mineral de Lota, en la región minera vecina y a las principales fábricas de Santiago y Valparaiso.

Actividades estudiantiles,-Organizados en un Centro, los estudiantes de Quimica Industrial han llevado a electo diversas labores cuya repercusión ha sido apreciable tanto para ellos mismos, como para el mejor conocimiento de la Escuela. Entre otras iniciativas han hecho práctica la de mantener un periódico cientifico y de actualidades, El Universitario. que ha reemplazado a la revista elngenieria Quimica.

Ante el año 1924.-El término del año 1923 encuentra a la Escuela en safisfactorias condiciones para la atención de la enseñanza que suministra.

Salvo en lo que respecta al Laboratorio de Fisica, que aun funciona en el local del Liceo de Hombres. los restantes laboratorios se hallan instalados en su propio edificio y están habilitados para el desempeño de su misión. También lo está el más arriba mencionado.

La Escuela pudo constatar, además, a fines de 1923. la terminación de los estudios de cuatro jóvenes, dos de los cuales obtuvieron inmediatamente su tifulo de Ingenieros Químicos Industriales.

No es posible, empero, dejar de consignar que aun no se modifica el criterio general con que se ha mirado el funcionamiento de la Escuela y que, a pesar de los fines de servicio de la economía y de la producción nacionales. que persigue. no ha conducido aún al incremento necesario y apreciable de la concurrencia de alumnos.

Curso de Ciencias Económicas y Comerciales. - Este curso, a cargo del doctor Carlos Keller R., constiluye, por su carácter de generalidad y por su tendencia práctica, una verdadera novedad en la enseñanza universitaria chilena.

Es ésta una cátedra libre cuyo desarrollo durará el término de un año escolar: su matricula, en su mayor parte integrada por jóvenes que tienen dedicadas sus actividades al mundo del comercio y de la industria, revela el acierto que ha significado la idea de su mantenimiento. El siguiente es el Programa general del Curso de Ciencias Económicas y Comerciales:

Primer Semestre: Economia general: Historia de la Economía: Geografia económica: Teoría de la moneda: Bancos y bolsas; Seminario económico. Segundo semestre: Economia general: Legislación social: Hacienda pública: Organización mercantil: Seminario económico. 
Los ramos del primer semestre comprenden las siguientes malerias: Economia general: Génesis del capitalismo moderno: Fundamentos del capitalismo moderno (producción, distribución, empresas capitalistas, consumo, crisis económicas). Historia de la Economia: Introducción: Sistemas económicos exóticos: Economia medioeval: Mercantilismo: Sistema natural: Escuela histórica; Escuela teórico-abstracta: Escuela evolucionista: las tendencias actuales de la Economia Politica. Sociologia: Introducción; la génesis de la sociedad: la sociedad occidental: (ideas fundamentales, el Estado, la cultura, la economia). Geografia económica: Parte general (las bases naturales, las bases politicas, el tráfico mundial, geografia de los pueblos y de las culturas); parte especial (Europa. Asia, Australia, África. América, Chile). Teoría de la moneda: la génesis de la moneda: legislación monetaria de las naciones más importantes, legislación monelaria de Chile, los Ban$\cos$ y su historia. leoria y legislación, las Bolsas y su historia, teoria y legislación. Seminario económico: Se harán en êl los trabajos prácticos y tendrán lugar las discusiones de libros. etc.. relacionado todo con la economia nacional y regional.

Extensión Universitaria. - Cuatro conferencias püblicas se han dictado en el aula de la Extensión Universitaria durante el año de 1924: y son ellas: la del doclor Tomás Mancini, acerca de slas bases de la fuerza y grandeza de Italia : la del doctor Luis Vargas Salcedo, sobre aLos fenómenos del rejuvenecimientor: la del doctor Carlos Charlín Correa, sobre ePasteur, el hombre, y la de Pedro Prado, titulada .El poeta Manuel Magallanes Moure.

Circulo de Lecturas.-En un ambiente más reducido e intimo que la Extensión Universitaria, el Círculo de Lecturas desarrolló en 1923 una labor muy continua y justamente apreciada por los que concurrieron a sus sesiones. El programa de este Departamento universitario para el mes que comienza se compone de las cuatro disertaciones siguientes:

3 de Junio: Enrique Molina, comentarios a .Mahatma Ganghi, de Romain Rolland.

10 de Junio: Abraham Valenzuela, comentarios sobre .Anatole Francer de G. Michaud.

17 de Junio: Luis D. Cruz Ocampo. comentarios sobre .El Banquetes de Platón.

24 de Junio: Juana Riffo de Mayorga. comentarios sobre La mujer y el trabajo, por Oliva Schreiner.

Cursos Libres de Filosofia.-Entre los cursos generales que están obligados a seguir todos los alumnos de la Universidad de Concepción. figuran los de Filosofía, a cargo de los profesores señores Enrique Molina y Enrique L. Marshall. Puede seguir el desarrollo de estas cátedras libres, sin necesidad de matricularse previamente, cualquiera persona, aun ajena a la Universidad.

Iniciaron su funcionamiento en el pasado mes de Mayo con asistencia numerosisima. 
Prołrama del Curso de Fllosofia que dictará el profesor don Enrique Marshall

1. Filosofia y Religión.-Sus relaciones consideradas históricamente. Sus relaciones actuales.

2. Ciencia y Filosofia.-Sus relaciones. Posición relativa actual de ambas disciplinas.

3. Creación artistica y concepción metafisica,-Sus relaciones desde el punto de vista psicológico.

4. El problema lógico.-Deducción e Inducciōn. Doctrina de Globot sobre el carácter unitario del razonamiento.

5. Filosofia Cientifica.-El método y el valor de las conclusiones de las diversas ciencias.

6. La metafisica. - Su objeto. Sus fundamentos. Posibilidad de la metafísica. Discusión de las objeciones de los positivistas y de Kant. La materia. La vida. El espiritu. Relaciones entre el alma y el cuerpo. Posibilidad de la inmortalidad del alma. Dios.

7. Teoria del conocimiento.-Principales teorias relativas al origen y al alcance de nuestros conocimientos.

8. El problema éfico.-La moral y sus relaciones con la metafísica. Moral teórica y moral aplicada. Las grandes doctrinas de la moral leórica. Moral aplicada o teoría de los deberes y los derechos.

9. El problemo esfético.-Nociones generales sobre el arte y la belleza

Programa del Curso de Filosofía que dictará el profesor don Enrique Molina

1. Filosofia francesa contemporánea: Introducción.-La Filosofia del siglo XIX.

2. Estudio especial sobre la filosofia de Guyau: La personalidad del filósofo. La estética. La moral. La educación y la religión.

3. Estudio especial sobre la filosofia de Bergson: El problema del método. El método intituivo. La libertad. La espiritualidad del alma. La vida.

4. Estudio de otras corrientes contemporáneas del pensamiento. 